\title{
TRANSMISSION ELECTRON MICROSCOPIC EXAMINATION OF THE HEALING POWER EFFECT OF MILLED TEETH VERSUS BETA-TRI CALCIUM PHOSPHATE GRAFTED IN CALVARIAL BONE DEFECT IN RATS
}

\author{
Ghada Mohamed Nasr Hassan ${ }^{1}$, Laila Sadek Ghali², Heba Abdullfattah Elsaied Ahmed ${ }^{3}$
}

DOI: $10.21608 / d s u .2020 .15695 .1007$

Manuscript ID: DSU-1908-1007

\section{KEYWORDS}

Beta tricalcium phosphate.

Bone graft material,

Milled teeth,

Transmission electron

microscope
- E-mail address: ghhassan90@gmail.com

1. Dentist at Zagazig University Hospitals

2. Prof. of Oral Biology, Faculty of Oral and Dental Medicine, Cairo University Dean of Faculty of Oral and Dental Medicine, Saini University (Kantara)

3. Lecturer of Oral Biology, Faculty of Dentistry, Suez Canal University

\section{ABSTRACT}

Aim: to evaluate the effect of milled teeth versus beta tricalcium phosphate bone graft material on new bone formation at the cell level using transmission electron microscope Materials and methods: Forty-five adult male albino rats, were divided into three main groups $(\mathrm{n}=15)$; control and two experimental groups. Under general anesthesia, $1.5 \mathrm{~cm}$ incision was done exposing the cranial bone. Then two noncritical size bone defects were created one in each parital sides of the rat calvarial bone. In Group I (control group): the bilateral calvarial bony defects were left to heal spontaneously. In Group II the bilateral calvarial bony defects completely filled with $\beta$-TCP. In Group III: the bilateral calvarial bony defects completely filled with tooth ash. Five rats from each group were sacrificed after 7, 15, and 30 days postoperatively. Results: tooth ash group: showed more new bone formation. Different types of cells appeared more active: multiple lymphocytes, fibroblast, osteoprogenitor cells, osteoblasts. Multinucleated osteoclasts with prominent vacuolated cytoplasm and ruffled border in Howship's lacunae were clearly seen. At day 30, disappearing of the tooth ash and infiltration of different types of cells; osteoprogenitor cells, bone lining cells, and osteoblasts while $\beta$-TCP particles were still seen in the sections. Conclusions: Bone activity, formation and maturity were ahead in tooth ash filled calvarial bony defects. Tooth ash had a role in the stimulation of osteoblastic activity in matrix formation and its mineralization.

\section{INTRODUCTION}

Bone tissue in the maxillofacial region plays important roles in keeping facial function and appearance. Bone regeneration using bone graft materials is becoming a common procedure ${ }^{(1)}$ The most ideal materials for bone regeneration are autogenous bone. Still, the main limitation to autogenous bone grafts is the inability to harvest large amounts of tissue. Also, complications in the donor area are abundant, and resorption after graft is substantial. Therefore, the bone substitutes include allogenic, xenogeneic, and alloplastic materials that have been developed and used in clinics ${ }^{(2)}$

$\beta$-TCP has been widely used as a bone substitute material, with the advantage of its biodegradability, harmlessness, and relatively inexpensive. It interacts actively with the blood clot after a fresh bony defect, and starts its osteoconductive action immediately. So; it is nowadays 
widely used for socket preservation after tooth extraction, as it was found to be very beneficial in keeping the bone height and width, and in slowing down the shrinkage associated with healing ${ }^{(3)}$

Recently; researchers choose autogenous tooth bone graft (AutoBT) which allows both formations of new bone and is steadily observed to be replaced by bone without compromising on the bone-regeneration capacity ${ }^{(4)}$ Human tooth is a rich source of stem cells, matrix, trace metal ions, and growth factors ${ }^{(5)}$ Although the tissue structures of bone and dentin are different, the ratio of the organic and inorganic contents is almost similar. Dentin also contains some growth factors common to bone, namely, insulin-like growth factor-II, bone morphogenetic protein (BMP), and transforming growth factor-beta (6) Furthermore, Dentin contains varieties of proteins that are similar to bone, namely, osteopontin, bone sialoproteins, dentin sialoproteins, osterix, and osteocalcin due to which it was considered as an effective alternative bone grafting material ${ }^{(7)}$.

From this point the present study aimed to evaluate the effect of milled teeth versus beta tricalcium phosphate bone graft material ( $\beta$-TCP) on new bone formation at the cell level using transmission electron microscope

\section{MATERIALS AND METHODS}

This study was conducted after approval of ethical committee no. 2/2017, Faculty of dentistry, Suez Canal University, animal care and handling was in accordance Helsinki declaration for animal use. The study was conducted on 45 adult male albino rats, weighting 150-200 g. Animals labeled and kept in their respective cages at room temperature with automatic light control and free access to food (rat chow) and water. The animals were kept in the animal house of the Faculty of Dentistry, Suez Canal University.
The study was conducted on 45 adult male albino rats, weighing $150-200 \mathrm{~g}$. Animals were divided into three main groups; control group and two experimental groups. Following the surgical protocol used by Abdullah WA ${ }^{(8)}$, all surgeries were done under general anesthesia, an approximately $1.5 \mathrm{~cm}$ incision was done to expose the cranial bone. Then two noncritical size bone defects ( $3 \mathrm{~mm}$ diameter) were created one in each parietal side of the rat calvarial bone. The calvarial defects were created primarily by dental trephine using low speed surgical drill and under copious saline irrigation.

Five rats from each group were sacrificed after 7 , 15 and 30 days postoperatively.

Group I (control group): Consisted of 15 rats, bilateral calvarial bony defects (30 bony defects) were prepared and were left to heal spontaneously.

Group II: Consisted of 15 rats, bilateral calvarial bony defects ( 30 bony defects) were prepared and completely filled with beta tricalcium phosphate bone graft material ( $\beta$-TCP). (Kasios ${ }^{\circledR}$ TCF France with a particle size of 1000-2000um.)

Group III: Consisted of 15 rats, bilateral calvarial bony defects (30 bony defects) were prepared and completely filled with Milled Teeth (tooth ash) [Figure 1].

\section{Preparation of milled teeth bone graft material:}

Sound teeth extracted for orthodontic reason (premolar or 3rd molar teeth) were kept in normal saline and prepared following the protocol used in Collage of Dentistry, King Saud University, Riyadh, Saudi Arabia.as follows:

1. Teeth were cleansed by blade no. 15 to remove all attached soft tissues.

2. They were heated in a furnace at $950^{\circ} \mathrm{c}(1742 \mathrm{~F})$ for $30 \mathrm{~min}$ for proteins denaturation. 


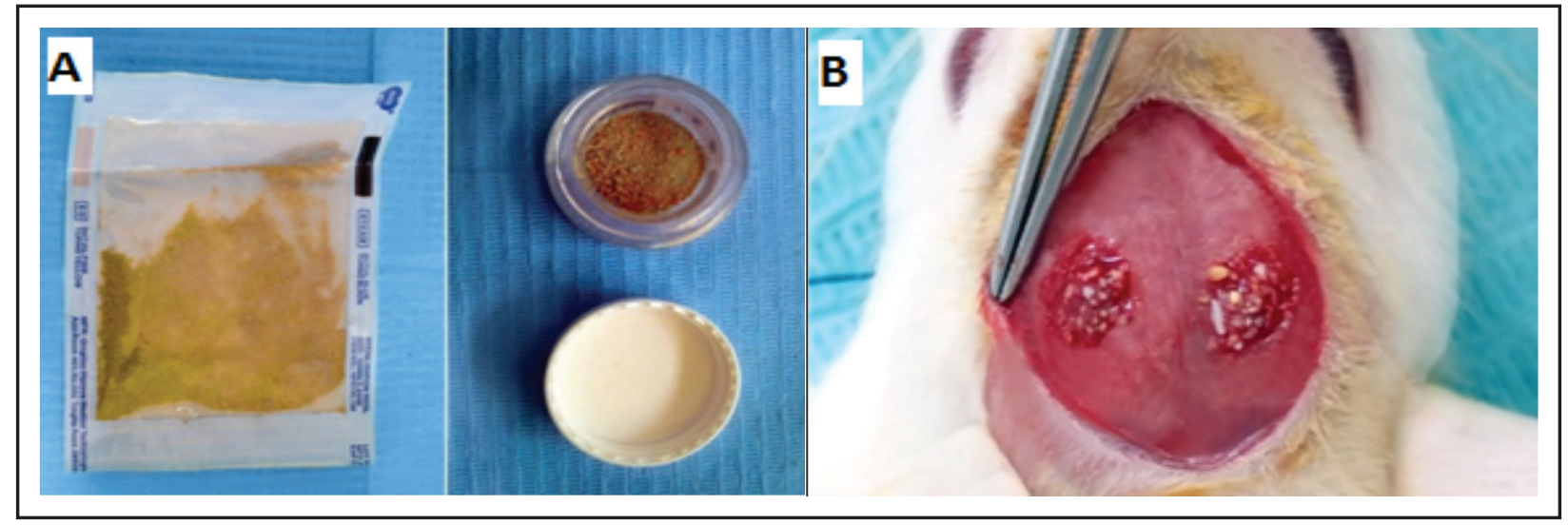

Fig. (1) Clinical photographs showing (A): Milled Teeth (tooth ash) bone graft material used in the study, (B): bilateral calvarial bony defects completely filled with Milled Teeth (tooth ash) bone graft material.

3. The teeth material was pulverized by means of freezing mechanical grinder. SPEX sample prep 6870 freezer miller machine was used. It is a cryogenic laboratory mill that cool samples to $-195.8^{\circ} \mathrm{c}(-320.4 \mathrm{~F})$ using liquid nitrogen and pulverize them by magnetically shuttling a steel impactor back and forth against two stationary end plugs. Preparation of milled teeth bone graft material was carried out in Collage of Dentistry, King Saud University, Riyadh, Saudi Arabia.

\section{Preparation for Transmission electron micro- scopic (TEM) examination: ${ }^{(9)}$}

The specimens were fixed in 3\% phosphate buffered glutaraldehyde for 4 hours, washed in the buffer for 24 hours at $4^{\circ} \mathrm{c}$ then they were decalcified in $10 \%$ ethylene diamine tetra acetic acid (EDTA) PH 7-7.3. For electron microscopic examination, very small pieces $(1 \mathrm{~mm} 3)$ from the healing tissue on the left side cut after complete decalcification using very sharp blade within the phosphate buffer from the corresponding sites to be examined with transmission electron microscope for ultra-structural examination of specimens after complete decalcification. Specimens washed in freshly prepared phos- phate buffer PH7, post fixed in $1 \%$ buffered osmium tetroxide, washed, dehydrated in ascending grades of ethanol and then embedded in epoxy resin. Ultrathin sections were cut and stained with uranyl acetate followed by lead citrate and examined with: Transmission electron microscope.

\section{RESULTS}

In the control group (Group I): active secretory fibroblasts and osteoblasts were clearly seen at day 7. At day 15, a lot of blood capillaries containing blood cells and lined with endothelium were encountered. Different types of bone cells; osteoprogenitor cells, bone lining cells and osteoblasts were arranged on the surface of new bone around the blood capillaries. At day 30, more new bone formation around blood vessel was seen. Increase in the number of bone cells; osteoprogenitor cells, bone lining cells, osteoblasts and osteocytes entrapped in lacunae on the new bone surface was observed [Figures :2-4].

In experimental group II: At day 7; multinucleated osteoclast cell with prominent vacuolated cytoplasm and ruffled border in Howship's lacunae were frequently seen. Different stages of osteoblastic 
differentiation were clearly seen in osteoid tissue. At day 15 , increase the number of active osteoblasts arranged around $\beta$-TCP material with large prominent nuclei and abundant secretory vesicles were seen. Young rounded osteocytes entrapped in lacunae and having cytoplasmic processes inside canaliculi were seen. At day 30, more new bone formation and bone cells were seen around $\beta$-TCP material which was still prominently found. Release of secretory granules by active osteoblast produced the electron dense area of the newly formed bone [figures:5-7].

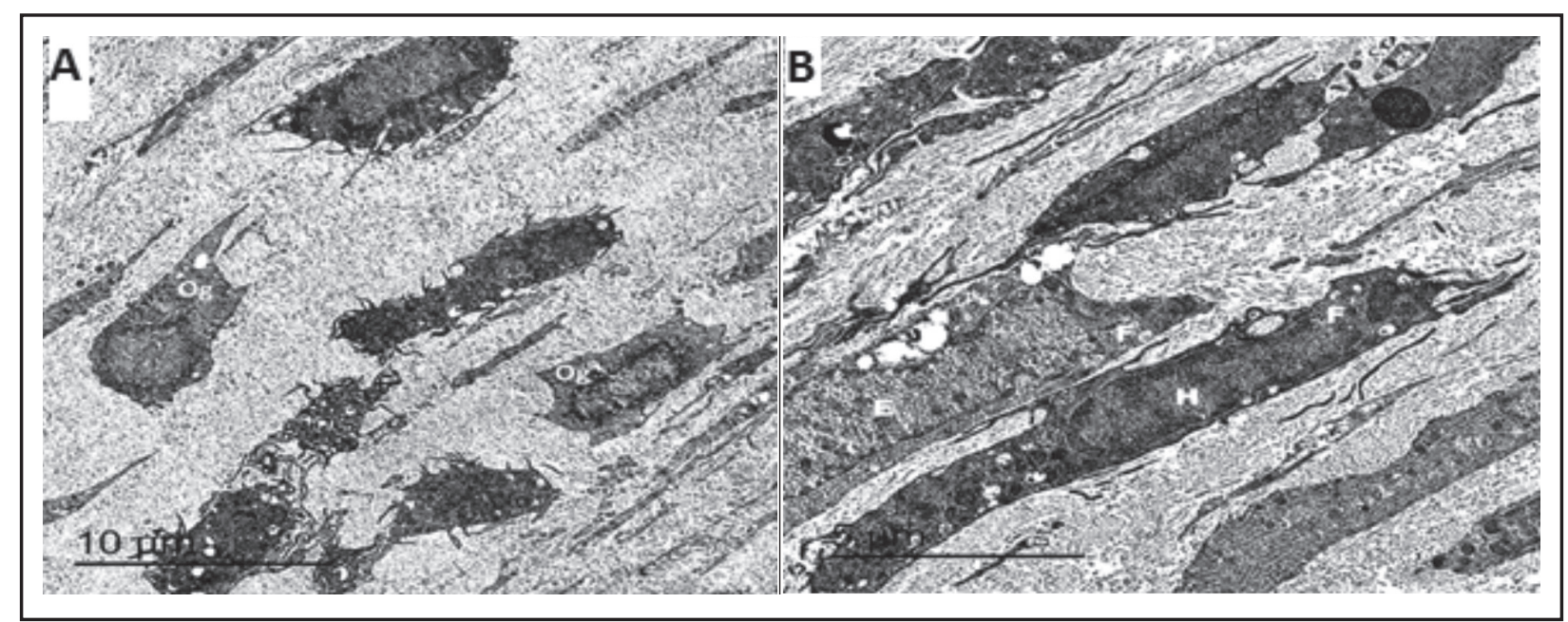

Fig. (2) Electron micrographs of the control group at day 7 post-surgically showing (A): differentiating osteoprogenitor cells (Og) with multiple cytoplasmic processes (TEM x600), (B): Active secretory fibroblasts (F) with different pattern of nuclear chromatin; Heterochromatic (H) and Euchromatic (E) nuclei clearly appear (TEM x1200).

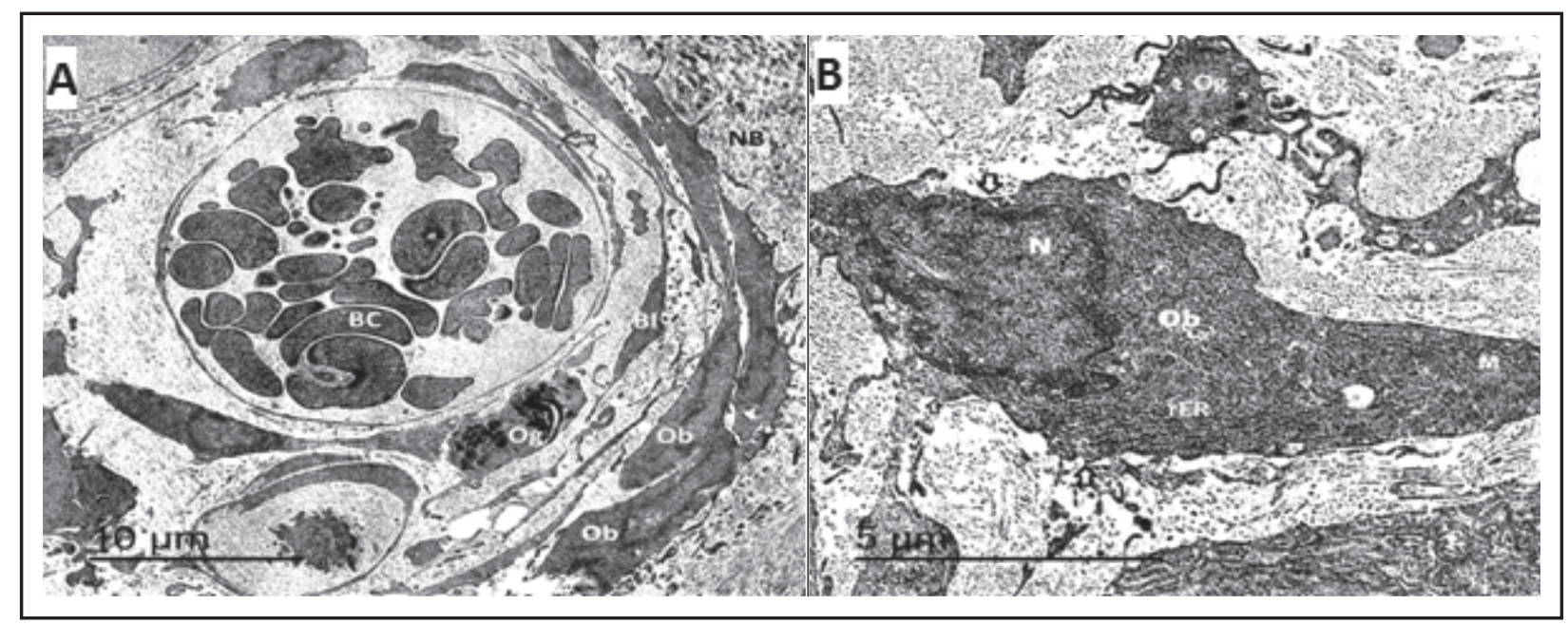

Fig. (3) Electron micrographs of the control group at day 15 post-surgically showing (A): blood capillaries containing blood cells (BC) and lined with endothelial cells (arrow). Different types of bone cells; osteo-proginator cells $(\mathrm{Og})$, bone lining cells $(\mathrm{Bl})$ and osteoblasts $(\mathrm{Ob})$ arranged on the surface of new bone (NB) around the blood capillaries (TEM x500), (B): active secretory osteoblast (Ob) with large open faced nucleus $(\mathrm{N})$, prominent rough endoplasmic reticulum (rER), Golgi bodies, mitochondria and vesicular exocytosis (arrows) are seen (TEM x1600) 


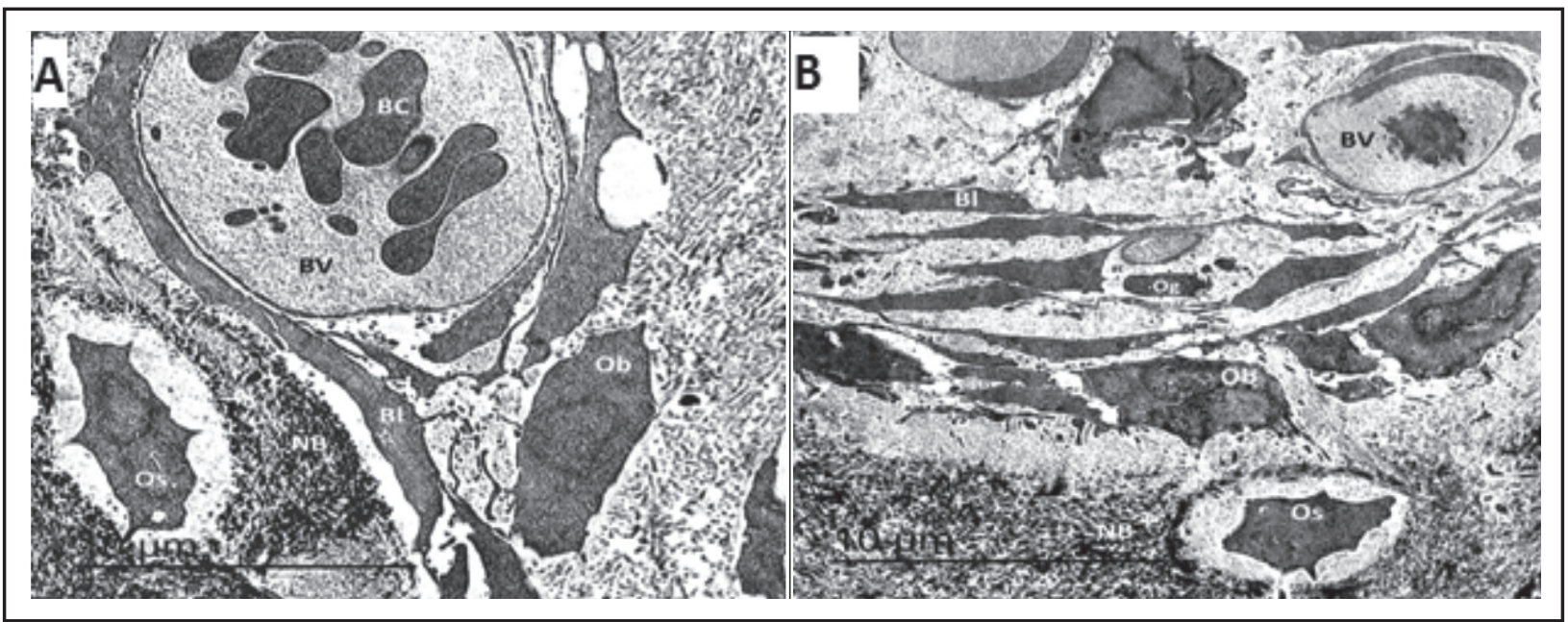

Fig. (4) Electron micrographs of the control group at day 30 post-surgically showing (A): new bone (NB) formation around blood vessel (BV) and different types of bone cells; bone lining cell (Bl), osteoblast $(\mathrm{Ob})$, and osteocyte (Os) with multiple short cytoplasmic processes entrapped in lacuna (TEM x800), (B): increasing the number of bone cells; osteo-proginator cells $(\mathrm{Og})$, bone lining cells $(\mathrm{Bl})$, osteoblasts $(\mathrm{Ob})$ and osteocyte $(\mathrm{Os})$ entrapped in lacuna, on the new bone surface $(\mathrm{NB})$ (TEM x1000).

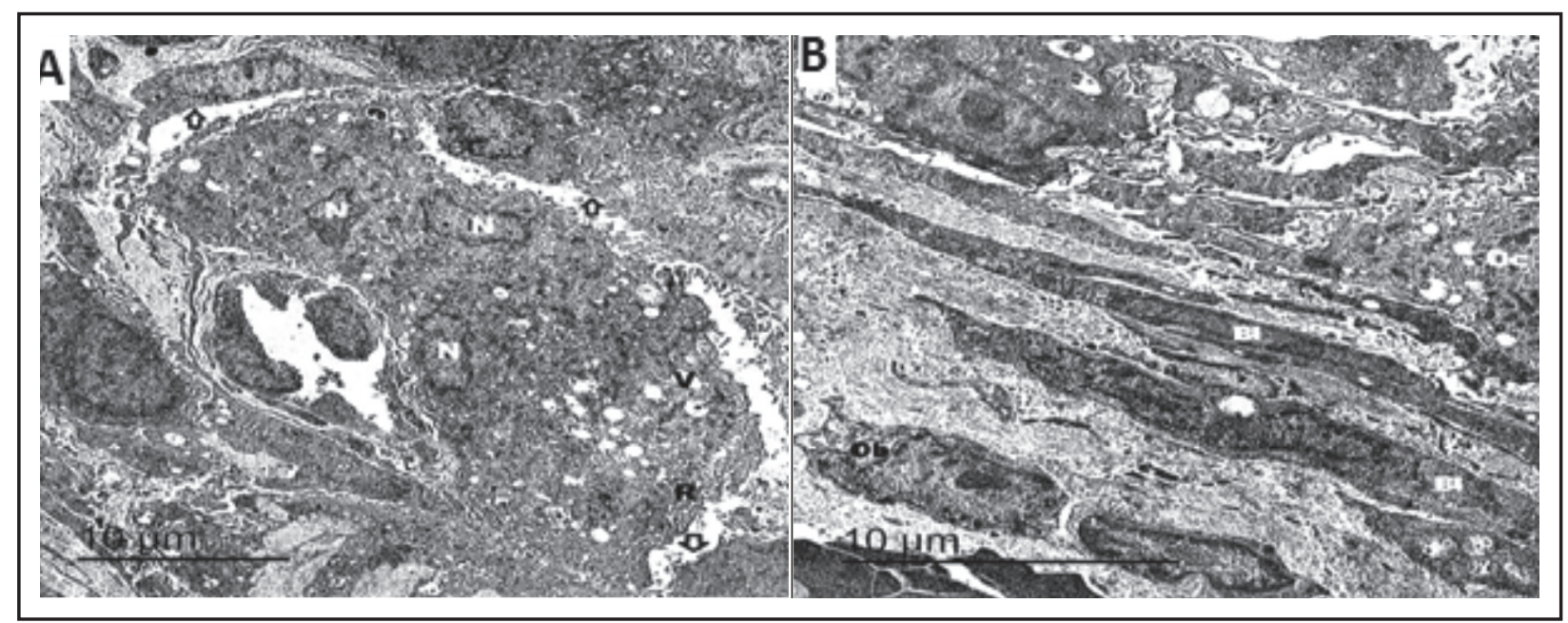

Fig. (5) Electron micrographs of the experimental group II at day 7 post-surgically showing (A): multinucleated (N) osteoclast (Oc) with prominent vacuolated cytoplasm (V) and ruffled border (R) in Howship's lacuna (arrows) (TEM x500), (B): bone lining cells with flat nuclear profile separating bone eating cell (osteoclast $(\mathrm{Oc})$ ) from bone forming cells (osteoblasts $(\mathrm{Ob})$ ) (TEM x800). 


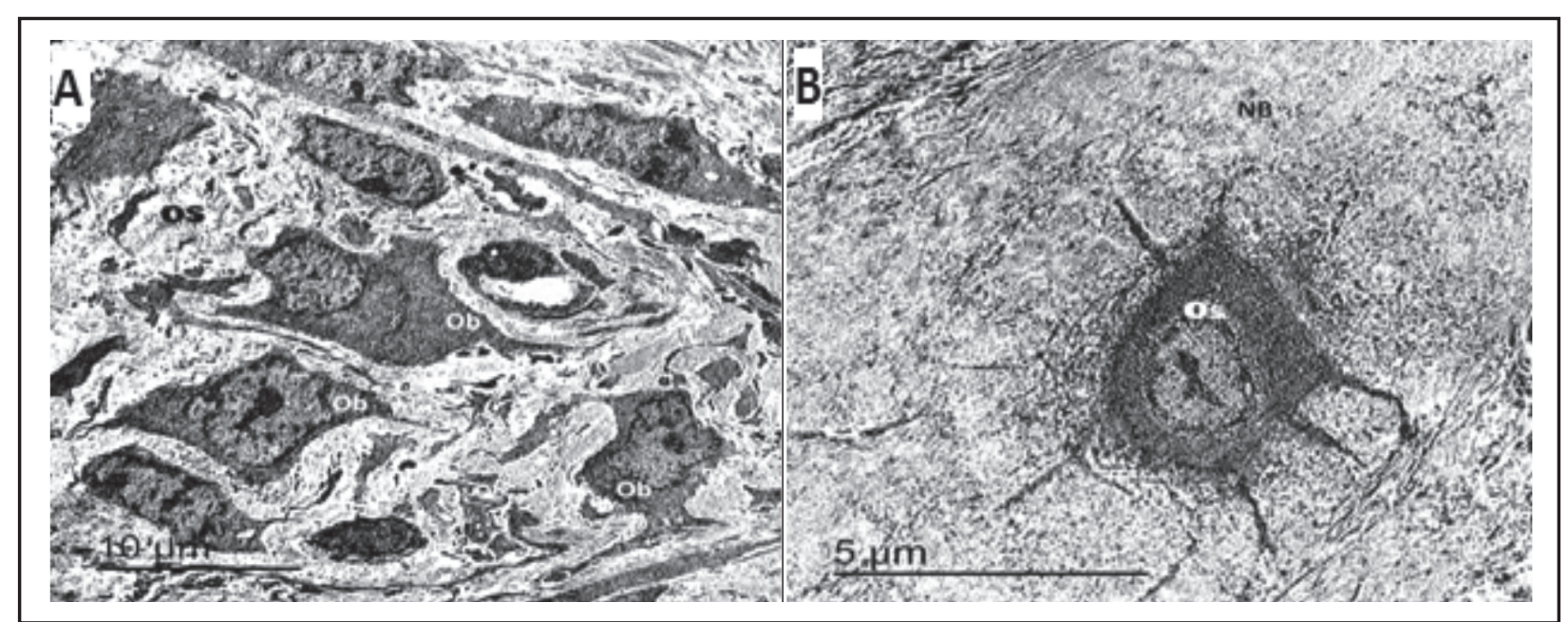

Fig. (6) Electron micrographs of the experimental group II at day 15 post-surgically showing (A): different stages of osteoblastic (Ob) differentiation clearly seen in osteoid tissue (OS) (TEM x500), (B): young rounded osteocyte (Os) entrapped in lacuna and having cytoplasmic processes inside canaliculi (TEM x1500).

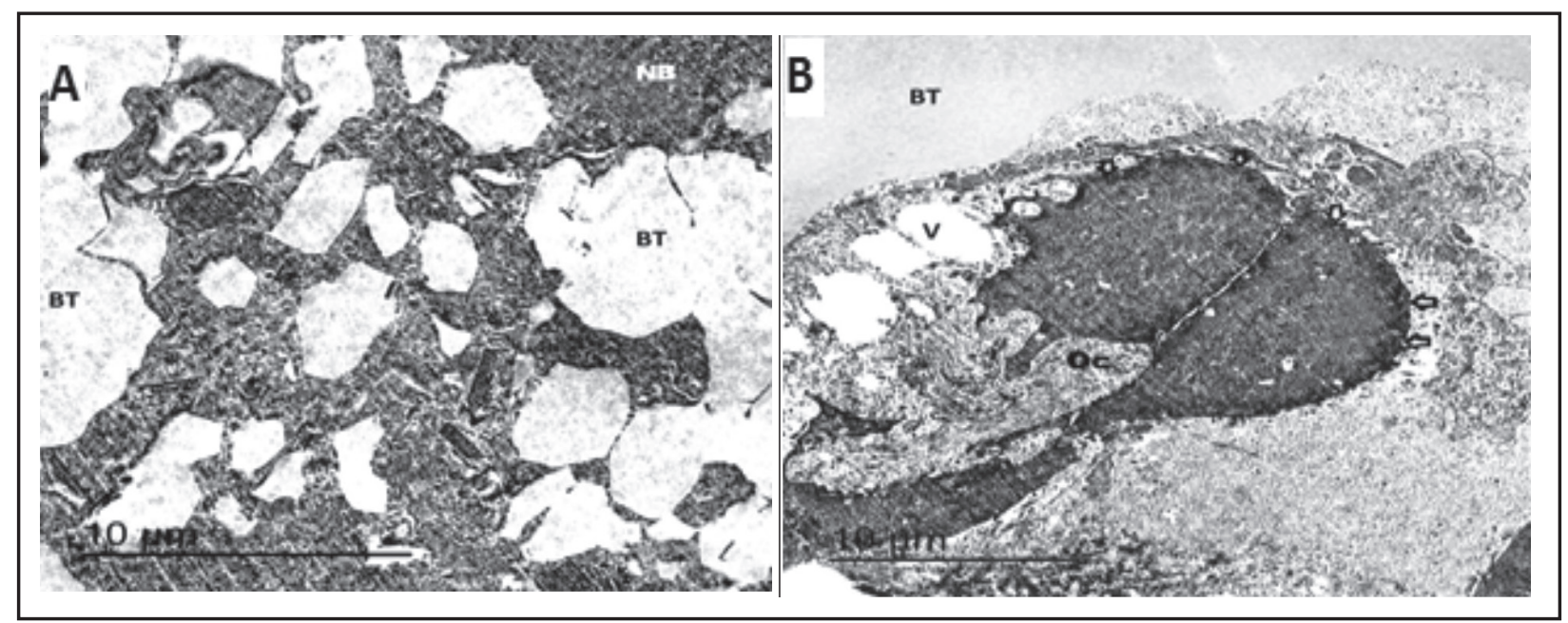

Fig. (7) Electron micrographs of the experimental group II at day 30 post-surgically showing (A): more new bone (NB) formation and bone cells seen around $\beta$-TCP material (BT) which is still prominently found (TEM x800), (B): Howship's lacuna (arrows) created by an osteoclast on the surface of $\beta$-TCP material (BT). Part of the osteoclast (Oc) with prominent vacuoles $(\mathrm{V})$ is moving away from this resorption site to another site on $\beta$-TCP surface (TEM x600).

In experimental group III: At day 7, new bone formation around tooth ash was seen. Dentin and dentinal tubules were prominently found. Different types of cells appeared more active: multiple lymphocytes, fibroblast, osteoprogenitor cells, osteoblasts and blood vessels were observed. Multinucleated osteoclasts with prominent vacu- olated cytoplasm and ruffled border in Howship's lacunae were clearly seen. At day 15, an increase in new bone formation and more active bone cells were seen. Multinucleated osteooclasts with prominent vacuolated cytoplasm were located on the partially resorbed tooth ash surface. At day 30, disappearing of the tooth ash and infiltration of different 
types of cells; osteoprogenitor cells, bone lining cells, and osteoblasts and the presence of blood vessels containing blood cells into tooth ash spaces was outstanding feature. Mature cuboidal osteoblasts were arranged on the surface of disappearing tooth ash. Spindle shaped osteocytes entrapped in lacunae within mineralized new bone were clearly observed [Figures: 8-10].

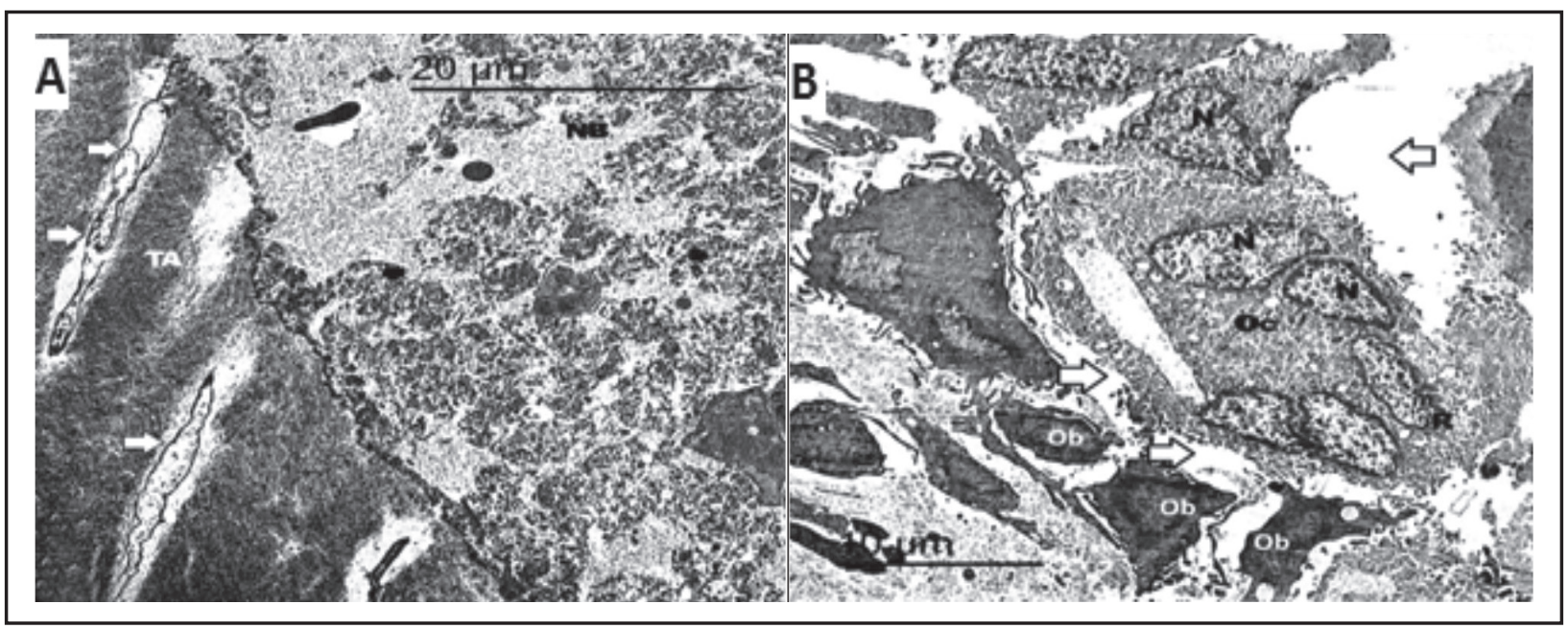

Fig. (8) Electron micrographs of the experimental group III at day 7 post-surgically showing (A): new bone formation (NB) around tooth ash (TA), dentin, and dentinal tubules (arrows) (TEM x400), (B): multinucleated (N) osteoclast (Oc) with prominent vacuolated cytoplasm and ruffled border (R) in Howship's lacuna (arrows) and cuboidal shaped osteoblasts (Ob) (TEM x500).

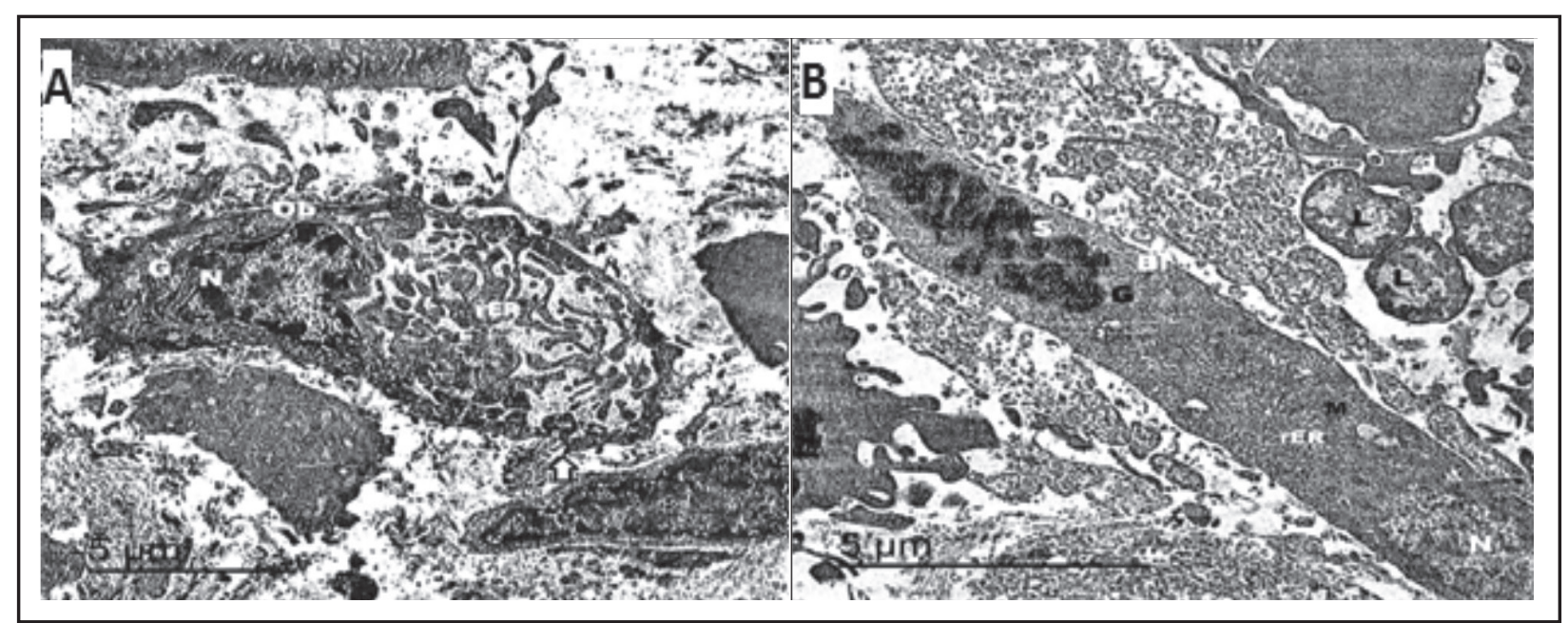

Fig. (9) Electron micrographs of the experimental group III at day 15 post-surgically showing (A): active secretory osteoblast (Ob) with large heterochromatic nucleus $(\mathrm{N})$, prominent and abundant rough endoplasmic reticulum (rER), Golgi bodies $(\mathrm{G})$, mitochondria and vesicular exocytosis (arrow) (TEM x1000), (B): active bone lining cell (Bl) with large Euochromatic nucleus $(\mathrm{N})$, prominent rough endoplasmic reticulum (rER), Golgi bodies, mitochondria $(\mathrm{M})$ and abundant secretory vesicles (S) and lymphocytes (L) (TEM x1500). 


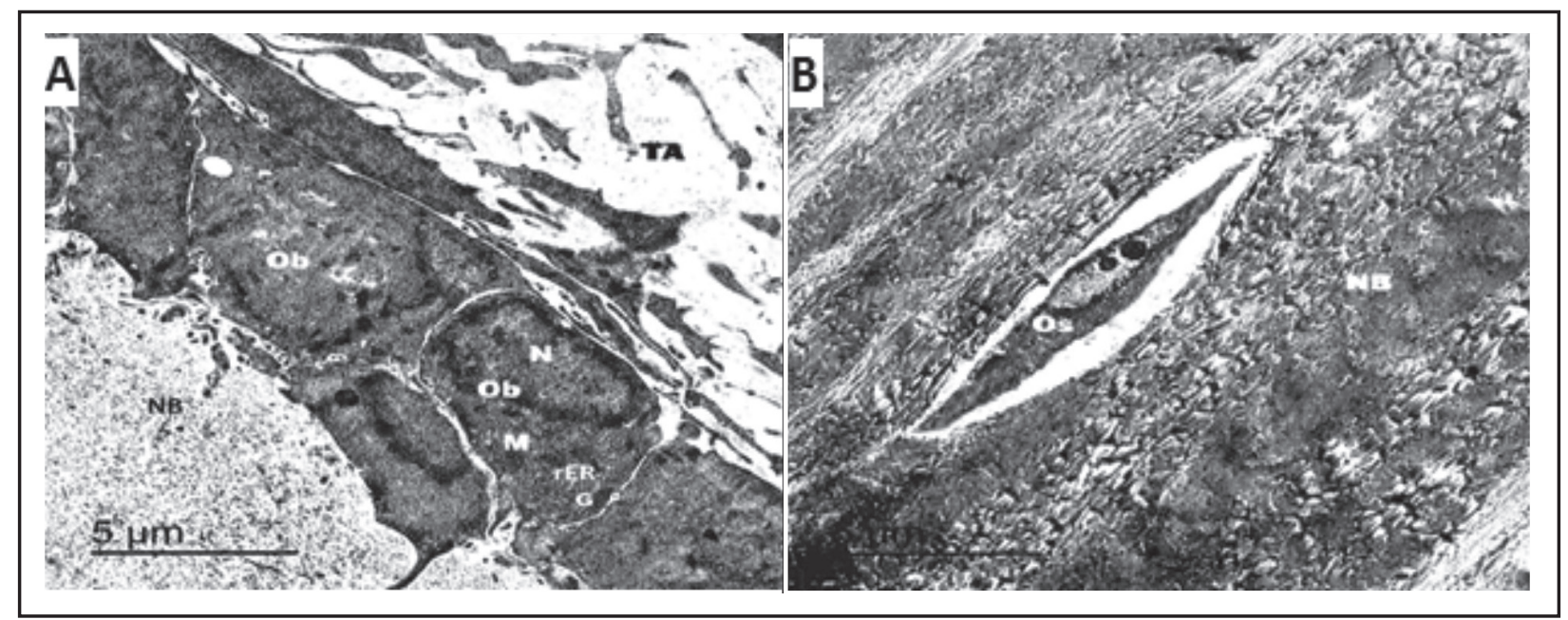

Fig. (10) Electron micrographs of the experimental group III at day 30 post-surgically showing (A): Single layer of mature cuboidal osteoblasts $(\mathrm{Ob})$ arranged on the surface of disappeared tooth ash (TA) (TEM x1000), (B): Spindle shape osteocyte (Os) entrapped into lacuna within mineralized new bone (NB) (TEM x1000).

\section{DISCUSSION}

The cranium (or skull) is a composite structure made up of the neurocranium, which surrounds and protects the brain, and the viscerocranium, which forms the skeleton of the face. The neurocranium can be subdivided into the cartilaginous part, which form base of the skull (or chondrocranium), and the membranous part, which forms cranial vault (or caldarium). The cranial vault consists mainly of the flat bones: paired frontal and parietal bones; the squamous parts of the temporal bone; and interparietal part of occipital bone. All of these bones are formed by intramembranous (IM) ossification. And this why using the claverial bone model in studying bone regeneration in maxillofacial region started to be widely used recently because of their similar origin and pattern of ossification ${ }^{(10)}$

Results of the present study showed more activity in the new bone formation process in the two experimental groups than in the control group with a superiority to the tooth ash group which were represented with the appearance of different types of more active cells: multiple lymphocytes, fibroblast, osteoprogenitor cells, osteoblasts and blood vessels were observed. Multinucleated osteoclasts with prominent vacuolated cytoplasm and ruffled border in Howship's lacunae were clearly seen surrounding the bone graft materials ( $\beta$-TCP, and tooth ash material)

These results could be explained by the effect of macroporosity of $\beta$-TCP which was also discussed by other studies, where it was stated that $\beta$-TCP provides a matrix, as its porosity allows increased blood flow, and cellular migration for enhanced healing. That permit the infiltration of osteogenic cells and angiogenesis: in addition, the porosity of the $\beta$-TCP is crucial to its rapid degradation, facilitating contact with host cells and resulting increased contact of osteoclastic cells with the material; the ability of these cells to penetrate and reabsorb the $\beta$-TCP contributes to the replacement of the biomaterial for bone tissue ${ }^{(11,12)}$. And this also come in agreement with the TEM results of the present study which revealed that the bone defects filled with $\beta$-TCP were infiltrated by osteoblastic cells in different stages and shapes, bone lining cells, osteo- 
cytes and the osteoclastic activity was prominently appeared.

Similarly, results of the present study came in agreement with other electron microscopic study showed that the bone graft was connected to the host bone by newly formed bone which was formed on the host bone surface of the dura mater side. The newly-formed bone showed a spongy-like appearance with many vascular spaces, or the bone forming surface had osteoblastic lacunae ${ }^{(13)}$

The present study results showed active osteoclast cells surrounding the graft material in the two experimental groups with prominence of osteoblast cells a osteoproginator cells to replace the resorbed bone graft material with new bone, with a support of newly formed blood vessels in the vicinity in the surrounding granulation tissues. With a superiority again to the tooth ash group which showed more resorption rate than the $\beta$-TCP granules. And again this came in agreement with older study used scanning electron microscope by Mastuda et $\mathrm{al}^{(13)}$ as they found that a part of the new bone lay in close contact with the bone graft material and under the scanning electron microscope, the quantity of the new bone covered on the sintered bone surface increased at the skin side, and the newly-formed bone intruded into the sintered bone than the synthetic bone graft material.

The present study results showed more activity in the bone eating cells as well as bone forming cells in the tooth ash group than in the $\beta$-TCP group which came in accordance with the results of Klein et $\mathrm{al}^{(14)}$, Hoogendoorn ${ }^{(15)}$, Matsuda et $\mathrm{al}^{(16)}$, as they stated that the bioresorbability of the synthetic hydroxyapatite is concerned with the temperature for crystallization, the crystallizable structure and the tricalcium phosphate (TCP) content in the hydroxyapatite. Which lead to delayed resorption and replacement of its particles with newly formed bone $^{(13-16)}$

\section{CONCLUSIONS}

Bone activity, formation and maturity were ahead in tooth ash filled calvarial bony defects than in $\beta$-TCP and control group

Tooth ash had a role in the stimulation of osteoblastic activity in matrix formation and its mineralization.

\section{ACKNOWLEDGEMENT}

Authors would like to thank Oral and Maxillofacial department, Collage of Dentistry, King Saud University for their help regarding milling of the teeth.

\section{Conflict of interest}

Authors have no conflict of interest to declare

\section{REFERENCES}

1. Fulin C, Tianqiu M, Kai T, Shujun C, Guicong D, Xiaoming G. Bone graft in the shape of human mandibular condyle reconstruction via seeding marrow-derived osteoblasts into porous coral in a nude mice Model. Scien. Art. J Oral Maxillofac surg 2002;60:1155-1159.

2. Kim YK, Kim SG, Bae JH, Um IW, Oh JS, Jeong KI. Guided bone regeneration using autogenous tooth bone graft in implant therapy: case series. Implant Dent. 2014;23(2):138-143.

3. Knabe C, Khattab DA, Kluk E, Struck R and Stiller M. Effect of a particulate and a putty-like tricalcium phosphate-based bone-grafting material on bone formation, volume stability and osteogenic marker expression after bilateral sinus floor augmentation in humans. J. Funct. Biomater. 2017; 8:1-22.

4. Kim YK, Kim SG, Byeon JH, et al. Development of a novel bone grafting material using autogenous teeth. Oral Surg Oral Med Oral Pathol Oral Radiol Endod. 2010;109(4):496-503.

5. Murata M, Akazawa T, Mitsugi M, Kabir MA. Autograft of dentin materials for bone regeneration. In: Pignatello R, editor. Advances in Biomaterials Sciences and Biomedical Applications. Croatia: InTech; Chapter 15. 2013; 391-403. 
6. Smith J. Vitality of the dentin-pulp complex in health and disease: Growth factors as key mediators. J Dent Educ 2003; 67:678-689.

7. Sarala C, Chauhan M, Sandhya S, Dharmendra H, Mitra N. Autogenous tooth bone graft: Ingenious bone regeneration material. Indian J Dent Sci 2018; 10:56-59.

8. Abdullah A. Evaluation of bone regenerative capacity in rats calverial bone defect using platlet rich fibrin with and without beta tri calcium phosphate bone graft material. Saudi Dent J 2016;28:109-117.

9. Ayub B, Wani H, Shoukat S, Para A, Ganguly S, Ali M. Specimen preparation for electron microscopy: an overview. J Environ Life Sci. 2017; 2:85-88.

10. Sung J, Ki S, Sang K. Development and Growth of the Normal Cranial Vault: An Embryologic Review. J Korean Neurosurg Soc 2016;59 (3) : 192-196.

11. Yoneda M, Terai H, Imai Y, Okada T, Nozaki K, Inoue H, Miyamoto S, Takaok, K. Repair of an intercalated long bone defect with a synthetic biodegradable bone-inducing implant. Biomaterials 2005; 26:5145-5152.
12. Munoz A, Silva E, Soto E, Cerda B, Ortiz M, Pozosguillen $\mathrm{A}$, Flores $\mathrm{H}$. Evaluation of decellularized matrix and $\mathrm{b}$ tricalcium phosphate as biomaterials for bone neoformation. in vivo study. Int. J. Morphol. 2017; 35:804-811.

13. Matsuda M, Kita S, Takekawa M, Ohtsubo S and Tsuyama K. Scanning electron and light microscopic observations on the healing process after sintered bone implantation in rats. Histol Histopathol 1995 10: 673-679.

14. Klein T, Driessen A, De-Groot K. and Hooff A. Biodegradation behavior of various calcium phosphate materials in bone tissue. J. Biomed. Mater. Res.1983; 17, 769-784.

15. Hoogendoom A. Long-term study of large ceramic implants (porous hydroxyapatite) in dog femora. Clin. Orthop.1984; 187,281-288.

16. Matsuda M, Satoh Y. and Ono K. Scanning electron microscopic and light microscopic observation on morphological changes of freeze-dried bone implantation in rats: Comparison with fresh autogenous bone transplantation. Histol. Histopathol.1992; 7, 393-403. 